\title{
Um Jogo Educativo na Web no Contexto do Ensino Fundamental
}

Carlos Alberto C. Lessa Filho, Instituto de Computação/UFAL, carloswgama@gmail.com Arturo Hernandez Domínguez, Instituto de Computação/UFAL, arturohd@uol.com.br Fábio Paraguaçu D. da Costa, Instituto de Computação /UFAL, fabioparagua2000@gmail.com Patrícia Virgínia Torres Albuquerque Oliveira, CESMAC, pattyvirginia@hotmail.com

Resumo: Este artigo tem como objetivo apresentar o Sim Investigador, um jogo que busca motivar o estudante através do lúdico com a construção e resolução de casos (histórias) envolvendo o conteúdo de uma disciplina, e desenvolvido para estudantes do ensino fundamental e médio. No Sim Investigador o estudante receberá o papel de um investigador no qual deverá solucionar casos utilizando seus conhecimentos aprendidos na escola ou colégio, como também poderá construir suas próprias histórias no contexto de um conteúdo programático proposto por um professor, se aprofundando no conteúdo estudado. Um estudo de caso foi realizado com 49 estudantes de três escolas. Os resultados obtidos no estudo de caso mostra que $69,38 \%$ dos estudantes informaram se sentir ainda mais motivados ao estudo com o uso do jogo Sim Investigador.

Palavras-Chave: jogos educativos digitais, educação a distância, motivação.

\section{An Educational Web Game in the Context of Elementary School}

Abstract: This paper aims to present the Sim Investigador, a game that seeks to motivate the learner using the ludic with the construction of cases and the resolution of cases about content of a discipline, and it was developed for students in the elementary school and secondary school. The students that play Sim Investigador will be an investigator that must to solve cases using their knowledge learned in school and high school, and they can also build their own stories related to a content proposed for a teacher. This way the student is going to learn more about the content studied. A casestudy had a participation of 49 students from three different schools. The results obtained in the case-study reveals that $69.38 \%$ of students felt more motivated to study after use the game Sim Investigador.

Keywords: digital educational games, distance education, motivation

\section{Introdução}

A existência de falhas na educação brasileira é algo observado ao longo dos anos. Através de uma pesquisa realizada pela Secretária de Educação Fundamental (Brasil, 1997) observou-se que os estudantes costumam não desenvolver interesse pelos estudos, apenas pela supervalorização das notas. Durante vários anos ocorreram tentativas de resolver os problemas através de investimentos em construção de mais escolas como solução do problema da educação, porém após discussões concluiu-se que o problema não está no número de escolas, mas sim na qualidade e no número de repetências, ocasionadas pelos estudantes que não possuíam bons desempenhos nas provas tradicionais (Schwartzman, 2005). Por meio de pesquisas realizadas pela Secretaria de Educação Fundamental é possível observar a ocorrência de esquecimento precoce dos conteúdos estudados e a falta de motivação, normalmente relacionados ao fato do estudante ser preparado para realizar uma prova ao invés de aprender o conteúdo.

Segundo Fiorentini e Miorim (1990) os alunos ao estudarem a disciplina muitas vezes sentem dificuldade em entender o que é passado em sala de aula, gerando reprovação ou não compreensão sobre como utilizar o conhecimento adquirido, não enxergando a sua importância. 
Para Piaget (Longaray et al, 2012) devemos considerar o lado afetivo e o cognitivo (conhecimento) como inseparáveis, pois é através do afetivo (emoções e ânimos) que conseguiremos desenvolver por completo o conhecimento. Por tanto, o interesse e a motivação são de extrema importância para estimular a busca de novos conhecimentos.

A Secretária de Estado da Educação (2008) ainda considera a importância de se unir a educação e tecnologia, de forma que o professor possa contar com novas ferramentas, que facilitem o aprendizado por meio da contextualização e inovação. Todavia, ainda há a resistência por parte de professores em utilizarem essas novas tecnologias pelo receio de falta de controle que terá sobre os estudantes.

Diante dessas dificuldades existentes no processo de aprendizagem, particularmente a falta de motivação, este projeto tem como objetivo contribuir com o desenvolvimento de um jogo que possa auxiliar tanto professores, quanto estudantes no contexto do ensino presencial ou à distância, através de resolução de casos contextualizados em uma narrativa associada ao conteúdo de uma disciplina.

\section{Jogos Educativos Digitais}

Para muitos os jogos, antigamente, eram apenas atividades que poderiam ser realizadas durante os intervalos das disciplinas ou nas aulas de Educação Física, todavia ao contrário do que se pensava, os jogos educativos podem ser aplicados em qualquer disciplina, onde os professores possam usar os jogos em sala de aula para que os estudantes aprendam de forma mais prazerosa, através de um recurso de seu cotidiano (Fernandes, 2010).

Segundo Vieira (Vieira Apud Silveira e Barone, 1998) a demonstração do conteúdo de uma disciplina usando recursos do cotidiano do estudante pode ajudar em uma melhor assimilação. Um exemplo deste método é o da maçã, utilizado com crianças na explicação da subtração na matemática. Os jogos na educação devem colaborar com a imaginação infantil, o processo de integração grupal, a emoção infantil e a construção do conhecimento. Desta forma, os jogos educativos podem explorar:

- Ludicidade: jogos de exercício, simbólicos e de construção;

- Aquisição de condutas cognitivas: aprimoramento do raciocínio prático, a discriminação e a associação de ideias;

- Desenvolvimento de habilidades funcionais: jogos que busquem aprimorar a aplicação de regras, localização, destreza, rapidez, força e concentração;

- Propiciar atividades sociais: uso de atividades que buscam a socialização;

- Aquisição de condutas afetivas: desenvolvam a confiança, autonomia e a iniciativa do jogador.

Os jogos educativos digitais também têm importante papel na aprendizagem. Segundo estudo realizado por Savi e Dra (2008), os jogos educativos digitais podem proporcionar:

- Efeito motivador: alta capacidade de divertir através do ambiente dinâmico e interativo;

- Facilidade na aprendizagem: facilitar a aprendizagem por meio de gráficos representando vários cenários;

- Desenvolvimento de habilidades cognitivas: elaborar estratégias para vencer os desafios do jogo;

- Aprendizagem por descoberta: desenvolver a capacidade de explorar, estimulando a curiosidade; 
- Experiências de novas identidades: explorar novas experiências, mundos e identidades através da imersão no jogo, como assumir o papel de um médico ou de estar em um avião;

- Socialização: aproximar os alunos com troca de informação e conhecimento;

- Coordenação Motora: desenvolvimento de coordenação motora.

- Comportamento expert: crianças tendem a se tornar "experts” em seus jogos, consequentemente se tornam "experts" no tema abordado.

A vantagem do uso de jogos educativos digitais está na possibilidade de exemplificar conteúdos com maior facilidade através de imagens, vídeos, textos e animações, porém a maioria jogos educativos são focados em um tema especifico, dificultando seu uso em diferentes disciplinas ou conteúdos. Dessa forma, professor ou estudante podem optar para construir seus próprios jogos para atender suas necessidades. Esses jogos podem ser construídos através de kits conhecidos como engines (Ribeiro et al, 2006). Além da possibilidade de construção de jogos, os professores podem optar pelo desenvolvimento de software educacional através de recursos multimídia como imagens, texto, vídeos e sons (Falkembach et al, 2006). Podemos citar algumas dessas ferramentas: Visual Class, Adobe Director e Multimedia ToolBook.

\section{Procedimentos Metodológicos}

A metodologia utilizada na pesquisa é apresentada nas seguintes fases:

Foi realizada uma pesquisa na literatura para compreender as dificuldades existentes no processo de aprendizagem por parte dos estudantes e dos professores, podendo ser identificado a falta de motivação e a dificuldade de abstração de onde tal conteúdo estudado será utilizado. Posteriormente foi realizada uma análise de jogos educativos digitais para observar características positivas que podem ser adotadas envolvendo os problemas de motivação, acompanhamento e contextualização do conteúdo de uma disciplina.

A modelagem do jogo educativo Sim Investigador voltado ao contexto do ensino fundamental foi realizada através da elaboração da arquitetura de sistemas, do diagrama de classes e do diagrama de estados utilizando a notação UML, que é uma linguagem visual para modelar sistemas de software baseados no paradigma da orientação a objetos (Guedes, 2011). O jogo Sim Investigador foi implementado para web utilizando a linguagem PHP (Hypertext Preprocessor), recursos HTML (HyperText Markup Language), CSS (Cascading Style Sheets) e Javascript armazenando os dados no Banco de Dados MySQL.

Um estudo de caso foi realizado com participação de 49 estudantes do ensino fundamental de Maceió (Alagoas) nas escolas: Nossa Senhora do Amparo, Santíssimo Senhor e Maria Montessori. O questionário aplicado buscava analisar fatores relacionados às metodologias de ensino utilizadas pelos professores, tais como dificuldades e recursos usados, como também perguntas relacionadas ao jogo Sim Investigador.

Para a aplicação do questionário foram criados dois casos (histórias) envolvendo as disciplinas de Geografia e Ciências respectivamente "Espião dos EUA: Regiões do Brasil" e "Morte do Professor Sean Lotters".

Após utilizarem e conhecerem os recursos do jogo, os participantes foram convidados a responder o questionário. 


\section{Sim Investigador: Um jogo educativo na web no contexto do ensino fundamental}

Nesta seção será apresentado o jogo Sim Investigador1 desenvolvido utilizando a linguagem PHP, banco de dados MySQL, HTML e CSS para a construção de páginas dinâmicas.

Sim Investigador (Figura 1) foi baseado no jogo de sucesso americano "Where in the world is Carmen Sandiego", no qual o jogador assume o papel de um detetive que precisa solucionar problemas utilizando seus conhecimentos em determinadas disciplinas, para capturar um fugitivo da lei. A partir deste ponto originou o nome do jogo: Sim (Simulação) e Investigador (papel do personagem)..

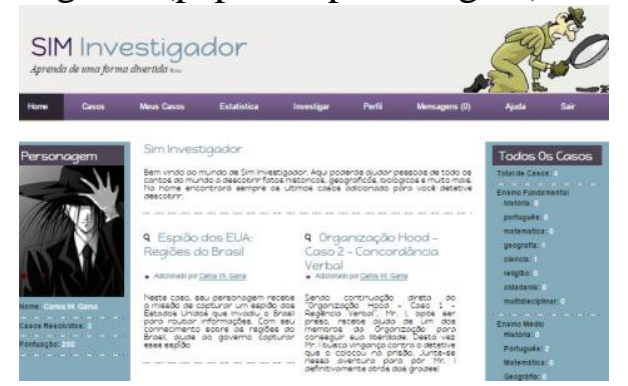

Figura 1 - A tela principal do jogo Sim Investigador

O jogo pretende auxiliar professores e estudantes no processo de ensino-aprendizagem. Para os estudantes, o jogo possibilita que estes aprofundem seus conhecimentos através de duas formas. A primeira, semelhante ao jogo citado anteriormente, o jogador deverá resolver um caso disponível no Sim Investigador. Um caso é formado por fases que contextualizam o conteúdo de uma disciplina através de personagens, imagens e enredo. Desta forma, após o estudante aprender operações básicas de matemática, poderá contextualizar esse conhecimento utilizando o jogo, que mostrará sua aplicação na vida real, por exemplo, para capturar um fugitivo da lei, o estudante deve utilizar seu conhecimento de subtração para calcular a distância entre duas cidades para encontrar a cidade mais próxima. Pretende-se dessa forma não apenas ajudar o estudante a aprender onde se aplica os conteúdos estudados, como também motiva-lo aos estudos utilizando os recursos lúdicos.

A segunda forma que um estudante pode utilizar o jogo para se aprofundar em um conhecimento, é através da construção de seus próprios casos. Segundo Seymour Papert (Kafai, 2006), o conhecimento para se alcançado por completo deve passar por um processo de construção. Diante desta análise, o jogo Sim Investigador permite que seus próprios usuários também possam construir os casos jogáveis no qual o usuário criador deverá estudar previamente um conteúdo da disciplina que deseja criar, montar um roteiro e questões que precisarão ser respondidas dentro do jogo para se concluir o caso. Este caso antes de ser aprovado, será avaliado por um professor e caso possua erros, será devolvido para o usuário criador com os comentários dos erros, fazendo com que o estudante entre em um processo de reflexão compreendendo o erro e o corrija.

O professor além de poder avaliar o conhecimento dos seus estudantes solicitando que eles criem casos, que serão avaliados por ele, também poderá acompanhar o desempenho de seus estudantes ao jogarem os demais casos criados. Como o jogo é aberto a todo o público na internet, foi desenvolvido um recurso que permite ao professor acompanhar os resultados exclusivos de seus estudantes. Sendo assim, se um professor de português solicitar que sua turma resolva dois casos envolvendo o conteúdo programático "Regência Verbal” e “Concordância Nominal”, através das pontuações obtidas pelos estudantes, o professor poderá ter uma visão geral e saber se os estudantes estão apresentando dificuldades em um conteúdo ou outro. 


\section{Exemplo de funcionamento do Sim Investigador}

Nesta seção serão apresentados exemplos do funcionamento do jogo Sim Investigador. O primeiro exemplo apresentará a criação de um caso (seção 5.1); O segundo mostrará como um usuário pode jogar um caso criado (seção 5.2); O último exemplo apresenta como o professor pode avaliar o desempenho de sua turma após jogarem um caso (seção $5.3)$.

\section{1 - Construções de Casos}

Um caso do Sim Investigador é uma história que assim como uma peça teatral, terá enredo, cenários e personagens. Esse enredo deverá contar uma história que envolva um conteúdo sobre uma disciplina e que a interação entre ela e os jogadores ocorra através de perguntas e respostas. Então para exemplificar como a construção de um caso no jogo Sim Investigador pode ser utilizada, vamos imaginar que um professor da disciplina de Ciências peça para seus estudantes criarem um caso envolvendo o conteúdo de ecologia envolvendo assuntos como habitat natural, biodiversidade e ecossistemas.

Antes de iniciar o processo de construção do caso, os estudantes em grupo ou individual de acordo com a solicitação do professor, deverão estudar através de livros e internet, e compreender o conteúdo de ecologia para estar aptos a criar um caso contextualizado sobre esse conteúdo. Durante este processo inicial, se os estudantes encontrarem alguma dúvida que não possuíam antes, por não conhecerem tão bem o conteúdo, podem tirar essa dúvida com o professor e inclusive será possível utilizar esta dúvida como uma forma de pergunta contextualizada na construção do caso para os demais jogadores responderem

Apenas após compreenderem bem o conteúdo e pensar em um enredo, os estudantes vão iniciar o processo de construção dentro do jogo através do menu Meus Casos.

Neste menu os estudantes visualizam seus casos, que podem estar nos seguintes status: "Rascunho", o caso está em construção; "Em avaliação”, o caso já foi construído, mas ainda não foi avaliado; "Aprovado", o caso já foi construído e aprovado por um avaliador; "Reprovado", o caso já foi construído e reprovado por um avaliador, e neste momento o estudante pode ler os comentários do avaliador e realizar os ajustes solicitados.

Ao criar um caso através desse menu, ele entrará como Rascunho e o usuário poderá cadastrar os personagens, cenários (fundos) e gerenciar o caso (história) através dos botões no topo da Figura 2. Em História (botão) poderá adicionar as fases, que são as diferentes telas do jogo com as falas e perguntas dos personagens; informar a qual disciplina o caso pertence podendo ser do Ensino Fundamental ou Ensino Médio; informar o número de erros que um jogador pode cometer dentro do jogo antes de falhar na missão; e uma breve descrição de até 500 caracteres informando sobre a história.

Ao adicionar uma nova fase do caso (Figura 3), o usuário criador deverá escolher o nome da fase, adicionar a imagem de fundo (opcional), a imagem do personagem que estiver falando (opcional), o texto que será exibido na fase e caso seja uma fase com pergunta, deve-se adicionar as alternativas que o usuário poderá escolher para prosseguir com o caso.

Após estruturar o caso completo, o jogador poderá através da tela principal do caso (Figura 2), visualizar como ficou o seu caso, podendo joga-lo; cancela-lo, o que fará perder tudo o que foi construído; salvar como rascunho para continuar mais tarde; e finalizar que fará o caso ser enviado para avaliação. 


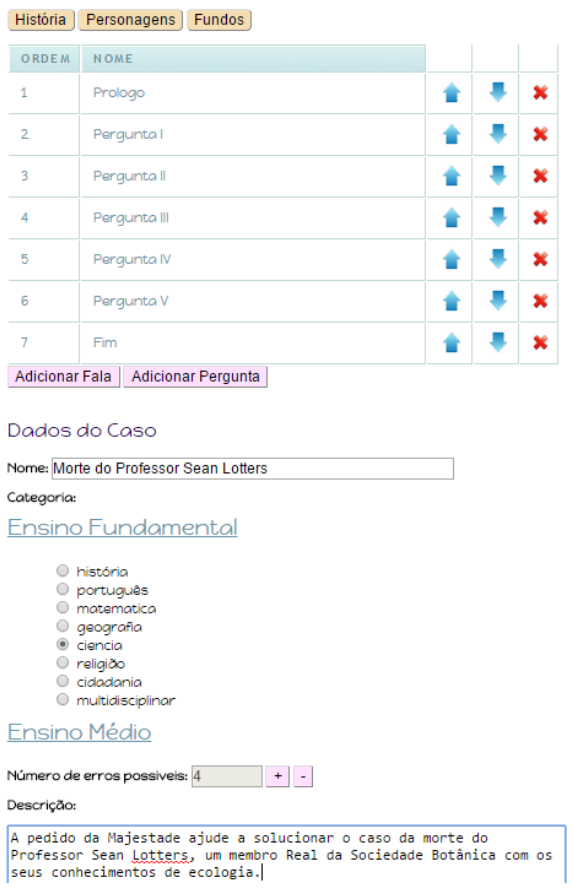

Figura 2 - Criando um caso

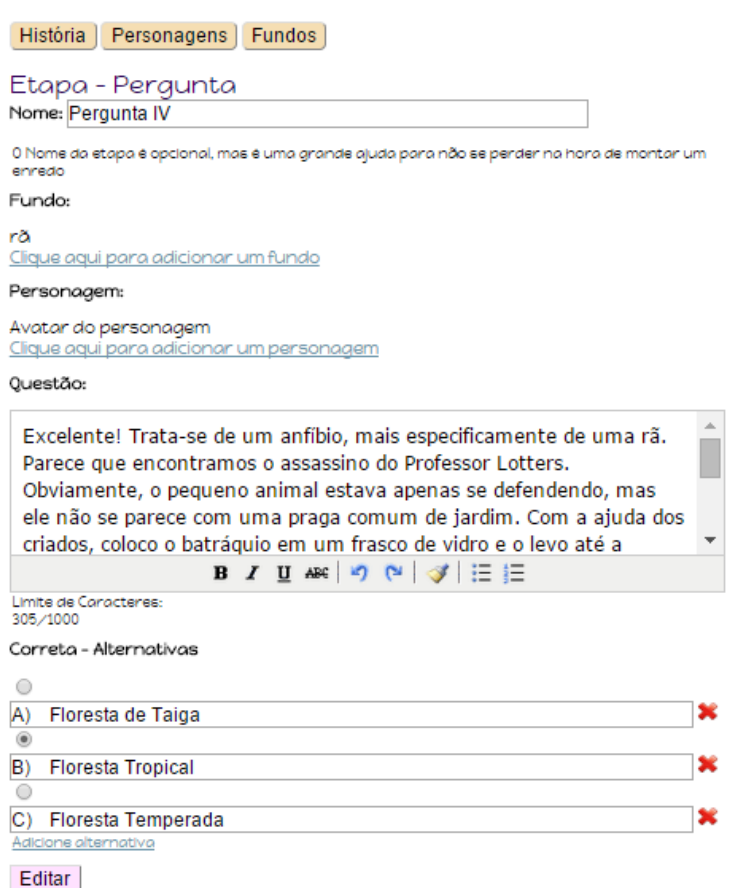

Figura 3 - Adicionando fase

A avaliação do caso pode ser realizada pelo professor dos estudantes, desde que solicite o acesso para avaliação. Neste momento o professor poderá avaliar o conhecimento que seus estudantes tiveram ao construir um novo caso e se apresentar falhas, deverá devolver o caso para eles, informando através da própria ferramenta o que deve ser corrigido, fazendo com que eles voltem a pesquisar, para solucionar o erro. Se o caso não tiver erros, poderá ser aprovado, para que os demais usuários joguem o caso criado.

\section{2 - Jogando um Caso}

O exemplo de como o Sim Investigador pode ser utilizado para o aprendizado através de jogar um caso, pode ser continuado diretamente após o exemplo anterior de construção. Posteriormente a construção dos casos pelos estudantes, o professor poderá sugerir que cada equipe ou estudante jogue os demais casos criados por seus colegas. Desta forma, cada estudante poderá aprender conteúdos que não havia observado durante a sua pesquisa.

Um estudante desta turma ao entrar no menu Casos, verá uma lista com todos os casos do Sim Investigador, e poderá procurar dentro da disciplina Ciências, os casos criados por seus colegas. Após encontrar o caso "Morte do Professor Sean Lottes”, criado por um colega de sua turma, poderá iniciar a sua resolução.

Na primeira fase (Figura 4), o jogador será apresentado ao caso, onde ficará sabendo sobre a morte de um botânico e que ele como detetive foi convidado a solucionar o mistério. À medida que o usuário avança no caso, encontrará fases com perguntas (Figura 5) que devem ser respondidas escolhendo uma das alternativas disponíveis.

Ao acertar uma pergunta, na fase seguinte, normalmente, existirá uma explicação do motivo pelo qual, aquela alternativa é correta, o que fará com que o jogador mesmo que não saiba o real motivo para aquela ser a alternativa correta, aprenda o motivo. Caso haja alguma dúvida após concluir o caso, esta dúvida poderá ser explicada pelo professor ou enviando uma mensagem para o criador do caso.

No final desse processo, o jogador terá visto conteúdos envolvendo ecologia de forma descontraída, que poderá incentivá-lo a pesquisar mais sobre o assunto visto. 


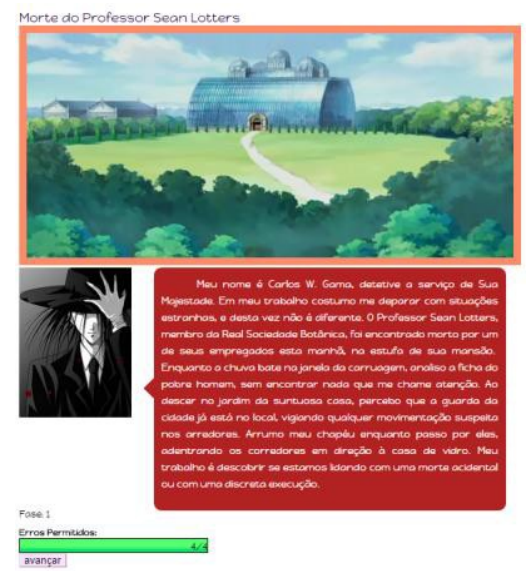

Figura 4 - Fase introdutória

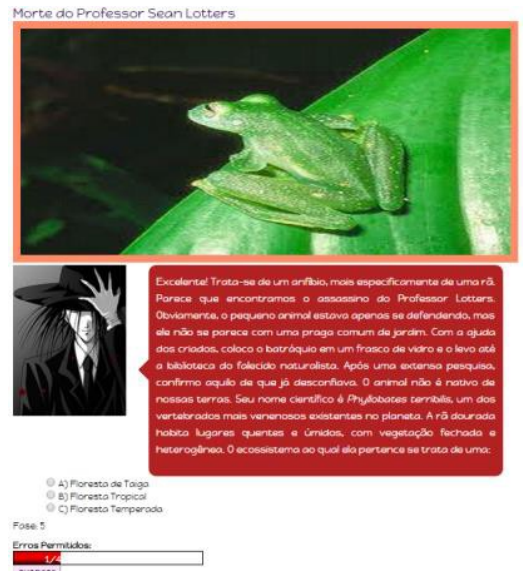

Figura 5 - Fase com pergunta

\section{3 - Investigar um Caso}

O recurso Investigar pode ser utilizado pelos professores para verificar o desempenho dos seus estudantes. Por tanto, após os estudantes terem construído um caso, que foi avaliado pelo professor e terem jogado os casos de seus colegas, agora o professor poderá avaliar o desempenho de seus estudantes na resolução dos casos.

Um exemplo que pode ser utilizado nesta seção é solicitar aos estudantes que criem casos, onde cada estudante trabalhará um conteúdo diferente da disciplina. Ao final, após os alunos criarem os casos e jogar os casos dos outros colegas, o professor poderá acessar o menu Investigar no topo do jogo.

Neste menu, o usuário poderá escolher o caso que deseja analisar, onde poderá analisar a data e a pontuação (Figura 6) que cada usuário teve ao resolver um caso divido por grupos. Os grupos fixos são: “Todos”, que listará todos os usuários do jogo Sim Investigador que já resolveram o caso selecionado; "Investigados”, que é um recurso onde os estudantes podem enviar ao professor a sua informação da pontuação e data de conclusão para que o professor não precise procurar pelos seus estudantes entre todos os usuários cadastrados no Sim Investigador.

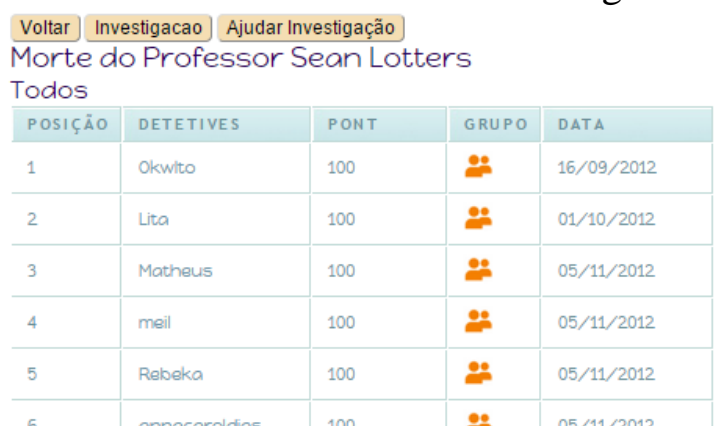

Figura 6 - Investigar caso

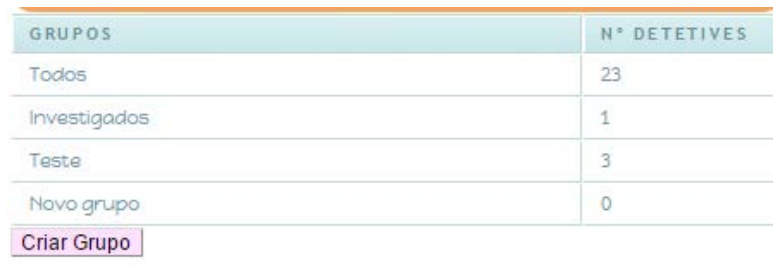

Figura 7 - Grupos

Na ocasião de um professor ter diferentes colégios ou turmas, poderá criar grupos (Figura 7), podendo assim dividir melhor os seus estudantes que pertencem a uma turma ou colégio.

Após ter todas as pontuações de seus estudantes, o professor poderá comparar as pontuações obtidas em cada caso que foi solicitado que seus estudantes jogassem. Observando que entre os casos resolvidos que envolvem assuntos diferentes de Ciências, o desempenho da pontuação sobre o assunto Sistema Solar não foi tão bom quanto os outros assuntos. Nesta ocasião o professor poderá notar que os seus estudantes desta turma possuem alguma dificuldade relacionada a este conteúdo, e que poderá ser corrigida (através da participação do professor) após esta análise. 
Outro fator que pode ser observado pelo professor através desse recurso, é na ocorrência de um estudante sair mal em todos os casos que o professor solicitou que ele jogasse, enquanto a turma teve um bom desempenho.

A partir destas informações, o professor poderá analisar qual estratégia seguir para ajudar nas dificuldades encontradas pelos seus estudantes.

\section{Modelagem do Sim Investigador}

Nesta seção, o diagrama de classes e o diagrama de estados do Sim Investigador são apresentados, utilizando a notação UML para modelagem desses artefatos.

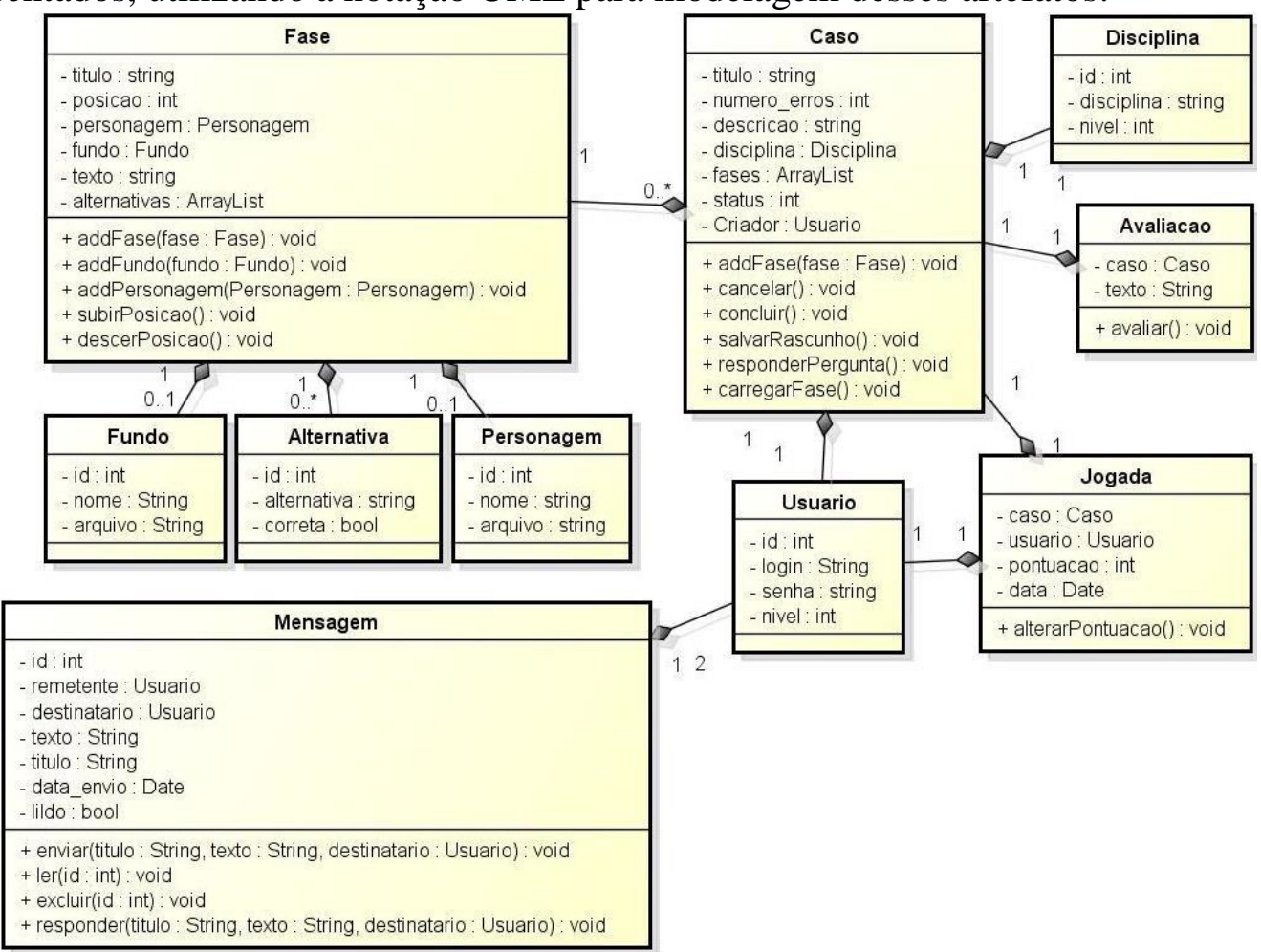

Figura 8 - Diagrama de Classes do Sim Investigador

O diagrama de classes (Figura 8) representa o domínio do jogo, onde podemos observar que as demais classes dependem da classe Caso. O usuário jogador poderá criar um caso utilizando as classes: Caso, Usuario, Fase, Fundo, Alternativa, Personagem e Disciplina. O usuário jogador poderá solucionar um caso através das classes: Jogada, Caso, Usuario, Disciplina, Fase, Fundo, Alternativa e Personagem. Para a troca de mensagens entre os usuários as classes utilizadas são: Mensagem e Usuario. E a avaliação do professor avaliador de um caso utiliza as classes: Avaliacao, Caso, Disciplina, Fase, Fundo, Alternativa e Personagem.

A classe Caso é a principal classe do domínio do jogo Sim Investigador e através do diagrama de estados (Figura 9), podemos observar o seu comportamento no jogo.

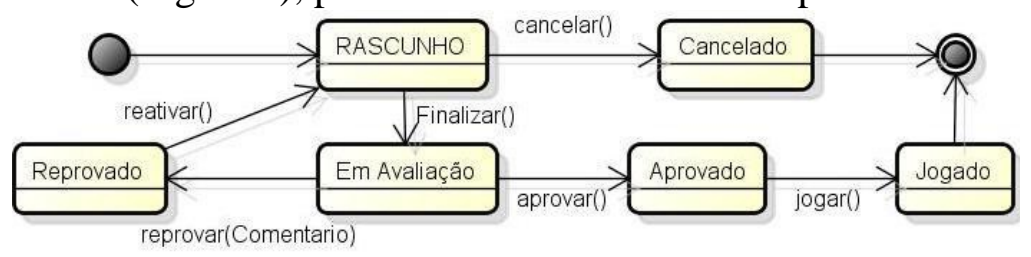

Figura 9 - Diagrama de Estados da classe Caso

Um caso quando criado é iniciado como rascunho. É neste momento que o usuário criador do caso poderá adicionar as fases, personagens, fundos e informações do caso. Caso deseje, poderá optar por cancelar o caso, que irá excluí-lo ou poderá finalizar o 
caso, para que um avaliador aprove ou reprove. Se reprovado, o caso poderá ser reativado pelo usuário criador, que voltará para o estado rascunho, onde será feito os ajustes necessários. Se aprovado, o caso estará pronto para ser jogado pelos diferentes usuários do jogo Sim Investigador.

\section{Resultados e Discussão}

Na etapa do estudo de caso, foram aplicados questionários com professores e estudantes para obter informações sobre os métodos de ensino utilizados e sobre o jogo Sim Investigador. Com as informações obtidas através dos questionários, pode-se perceber em relação ao ensino que a maioria dos estudantes (63\%), não consideram possuir dificuldades em aprender através de livros, explicações no quadro de forma abstrata ao contrário do que se esperava, todavia entre os estudantes que responderam que sentem dificuldade (32\%), pode-se observar que essas dificuldades estão vinculadas ao fato dos estudantes não conseguir assimilar o conteúdo da forma apresentada pelo professor e os demais estudantes (5\%) informaram que as vezes possuem dificuldades dependendo da disciplina. Também se pode observar o seguinte resultado, quando se fala em esquecimento precoce, $75 \%$ dos estudantes não se lembram do que estudaram no ano anterior, demonstrando preocupação com a nota ao invés do aprendizado.

Também se pode perceber em relação ao ensino que apenas 11 dos 49 estudantes informaram não se sentir motivados a estudar e 8 informaram que dependia da disciplina, já a maioria, 30 estudantes informaram que se sentem motivados aos estudos. Todavia 34 dos 49 estudantes informaram sentir ainda mais motivados ao estudo com o uso do jogo Sim Investigador e um estudante considerou que se sentiria mais motivado com a união do jogo e o professor no processo de ensino, aonde o professor explicaria as respostas dos casos e tirando dúvidas dos estudantes, enquanto avançavam juntos. Os professores também concordaram que o uso do lúdico é uma ótima forma de motivar os estudantes a se aproximarem mais do ensino e durante esta experiência, puderam perceber seus estudantes menos dispersos durante a aula.

Ao questionar os professores sobre a maior dificuldade encontrada ao apresentar o conteúdo para os estudantes, obteve-se como resposta a falta de recursos diferenciados para se usar em sala de aula e a dificuldade em como cativar a atenção do estudante.

Em relação ao jogo, ao verificar as opiniões sobre os estudantes construírem as histórias, pode-se ver que 46 dos 49 estudantes consideraram interessante a incorporação deste recurso. Já os professores além de gostarem, informaram que mesmo que um estudante não possua o conhecimento necessário, poderá adquiri-lo à medida que desenvolve a história.

Como sugestões de melhorias para o Sim Investigador, obtiveram-se informações relacionadas à melhoria no visual por parte dos professores e mais dinamismo por parte dos estudantes, como a possibilidade de controlar personagens em um cenário.

\section{Considerações Finais}

Este trabalho apresentou o jogo Sim Investigador tendo como objetivo motivar os estudantes aos estudos através de criação de histórias, facilitando a compreensão de como os conteúdos podem ser aplicados e possibilitar aos professores acompanharem o desenvolvimento de seus estudantes.

O jogo Sim Investigador tem como proposta possibilitar que o estudante aprofunde o seu conhecimento em um assunto através de construções de casos, que são histórias similares a uma peça teatral, envolvendo um conteúdo de uma disciplina. O jogo também possibilita uma aprendizagem através da resolução dos casos criados, aonde os jogadores necessitam aprofundar seu conhecimento através de pesquisas e estudos para 
estarem aptos a solucionar um caso. Além da resolução dos casos, os professores poderão acompanhar o desempenho dos seus alunos através da pontuação obtida pelos estudantes ao resolverem um caso.

Um estudo de caso foi realizado usando o Sim Investigador em diferentes turmas sendo analisados fatores relacionados ao ensino segundo a visão dos estudantes e professores. Em relação ao jogo, houve interesse tanto por parte dos professores quanto pelos estudantes, que não estão acostumados com recursos lúdicos no processo de ensino aprendizagem.

Como trabalhos futuros, deseja-se reformular o ambiente para melhorar seu visual, organizar melhor o controle e organização dos casos criados pelos estudantes e possibilitar a criação de histórias em ambientes 2D utilizando a engine Unity.

\section{Referências}

BRASIL. Parâmetros Curriculares Nacionais: Introdução aos Parâmetros Curriculares Nacionais. 1997. Disponível em:

<http://portal.mec.gov.br/seb/arquivos/pdf/livro01.pdf>, acesso em 25 out. 2014.

FALKEMBACH, G. A. M.; GELLER, M.; SILVEIRA M.S. N. Desenvolvimento de Jogos Educativos Digitais utilizando a Ferramenta de Autoria Multimídia: um estudo de caso com o ToolBook Instructor. RENOTE, V. 4, n. 1. p.1-10. 2006

FERNANDES, J. C. L. Educação digital: Utilização dos jogos de computador como ferramenta de auxilio à aprendizagem. Periódico Eletrônico da FATEC, v.1, n. 3, p. 88-97. 2010.

FIORENTINI, D.; MIORIM , M. Â. Uma reflexão sobre o uso de materiais concretos e jogos no Ensino da Matemática. In: BOLETIM SBEM-SP, ano 4, Nº 7, 1990.

GUEDES, G. T. A. UML 2: Uma Abordagem Prática. Editora Novatec, $2^{a}$ edição, 2011.

KAFAI, Y. B. et Al. The Cambridge Handbook of the Learning Sciences.

Cambridge University Press, 2006.

LONGARAY, A. N. C.; BEHAR, P. A.; LONGHI, M. T. Afetividade em um ambiente virtual de aprendizagem: um estudo sobre os indicadores pedagógico. In SBIE 2012.

Anais. 2012.

RIBEIRO, L. O. M.; TIMM, M. I.; ZARO, M. A. Modificações em jogos digitais e seu uso potencial como tecnologia educacional para o ensino de engenharia. RENOTE, $\mathrm{V}$. 64 n. 1. 2006.

SAVI, R.; DRA, V. R. U. Jogos digitais educacionais: benefícios e desafios. RENOTE, V. 6, n. 2. p.1-10. 2008.

SCHWARTZMAN, S. Os desafios da educação no Brasil. Os desafios da educação no Brasil. Rio de Janeiro, p 9-50. 2005.

SECRETÁRIA DE ESTADO DA EDUCACAO. O professor PDE e os desafios da Escola pública paranaense: produção didático-pedagógica. Governo do Estado do Paraná, Volume II, Curitiba 2008.

SILVEIRA, S. D.; BARONE, D. A. C. Jogos Educativos Computadorizados utilizando a abordagem algoritmo genético. In: IV Congresso RIBIE, Brasília. 1998. 